\title{
FORCE OF EVIL E AS DIVISÕES INTRA-CLASSE
}

\author{
Elder Kôei Itikawa Tanaka \\ Universidade de São Paulo
}

\begin{abstract}
Resumo: Esse artigo discute Force of Evil (Abraham Polonsky, 1948) com o objetivo de observar dois aspectos da narrativa: primeiro, a maneira como se configura no filme a perspectiva da esquerda política sobre os monopólios e o capitalismo; em segundo lugar, a visão do diretor quanto à questão da divisão intra-classes nos Estados Unidos da década de 1940.
\end{abstract}

Palavras-chave: Force of Evil. Abraham Polonsky. John Garfield. Divisões intra-classe. Capitalismo.

\section{Introdução}

Baseado no romance Tucker's People, de Ira Wolfert, Force of Evil ${ }^{1}$ (1948) é o primeiro trabalho de Abraham Polonsky como diretor. O filme tem como protagonista o ator John Garfield no papel de Joe Morse, um advogado ambicioso que trabalha para Ben Tucker (Roy Roberts) em Wall Street. Tucker é um gângster ex-traficante de bebida durante a Lei Seca, que quer dominar o mercado de jogos de azar de Nova Iorque. Tal monopólio, no entanto, afeta diretamente os negócios de Leo (Thomas Gomez), irmão de Joe, que sofre de problemas cardíacos e opera uma pequena banca de apostas ${ }^{2}$ na cidade. Dessa maneira, Joe procura alternativas para atingir as metas estabelecidas por seu chefe e, ao mesmo tempo, tenta salvar seu irmão da bancarrota.

Tanto Polonsky como Garfield faziam parte de um grupo denominado plebeians, uma geração de artistas e intelectuais de famílias de imigrantes da classe trabalhadora norteamericana. Tal geração via no desenvolvimento do aparato da indústria cultual uma

\footnotetext{
${ }^{1}$ Force of Evil é conhecido no Brasil por dois títulos distintos: "Força do Mal" e "Força Diabólica". Esse último, por sua vez, é homônimo do título em português de The Tingler (William Castle, 1959). A fim de evitarmos qualquer ambiguidade, utilizaremos o título original em inglês para nos referirmos à obra de Abraham Polonsky.

${ }^{2} \mathrm{O}$ termo em inglês utilizado no filme para definir o local onde se controlam as apostas do jogo é "bank". No entanto, para evitar a ambiguidade com a tradução para "banco", utilizaremos o termo "banca", mais comum no português brasileiro quando relacionado a jogos de azar.
} 
oportunidade de ganhar a vida como escritores ou artistas, deixando para trás o mundo do trabalho braçal dos pais ao ingressar em um universo próximo ao do trabalho intelectual aparentemente de classe média, mas com pouca garantia de emprego (DENNING, 1996, p. 60-61).

Os plebeians, por sua vez, eram parte da "Frente Cultural" (Cultural Front), um movimento cultural e político que se desenvolveu a partir do legado da Depressão vivida pelo país nos anos 1930. O crítico cultural norte-americano Michael Denning ressalta que o surgimento da "Frente Cultural" está ligado a três fatores principais. Pelo fato de serem filhos de imigrantes da classe trabalhadora, muitos dos trabalhadores da indústria cultural traziam para esse meio os valores passados por seus pais. Além disso, boa parte dos integrantes da Frente Cultural iniciou seu aprendizado na década de 1930, num período em que a consciência de classe era valorizada. Por último, no caso de Hollywood, muitos dos trabalhadores adquiriram uma determinada consciência de classe nesse período, visto que diretores, atores e roteiristas sofriam represálias por parte dos estúdios ao tentarem se organizar em sindicatos. O próprio filme Force of Evil só pode ser produzido porque foi realizado pela Enterprise Studios, uma produtora independente que oferecia aos atores e diretores parte dos lucros e atraiu membros proeminentes da esquerda norte-americana como Polonsky e Garfield (MUNBY, 1999, p. 124). Segundo Paul Buhle e Dave Wagner,

\begin{abstract}
a atmosfera de luta política está em todos os aspectos de Force of Evil, do script à produção, e até mesmo no contexto histórico. Como aponta Sklar, o enredo alveja diretamente o pescoço do monopólio, não apenas na loteria ilegal em Nova Iorque, mas, por implicação, dos grandes estúdios. No ano anterior, a Suprema Corte havia declarado os estúdios culpados por violarem a lei antitruste [Sherman Antitrust Act] e obrigou-os a abrir mão de cadeias de estúdios - o que viabilizou economicamente a realização de filmes de arte em estúdios independentes ${ }^{3}$ (BUHLE; WAGNER, 2001, p. 118).
\end{abstract}

Tendo em vista as condições de produção de Force of Evil, nosso objetivo com esse artigo é observar dois aspectos do filme. O primeiro é a maneira como nele se configura a perspectiva da esquerda sobre os monopólios e sobre o capitalismo. O segundo aspecto é a visão do diretor quanto à questão da divisão intra-classes - parte importante da pauta da crítica da esquerda à produção da Frente Cultural, segundo Denning. Daremos início às nossas considerações sobre o filme observando como Polonsky nos apresenta os personagens da narrativa e quais recursos técnicos o diretor utiliza na introdução do filme.

\footnotetext{
${ }^{3}$ Todas as obras citadas neste trabalho que não possuem tradução oficial para o português têm tradução nossa. As citações dos diálogos e da narração de Force of Evil têm como base as legendas do DVD.
} 


\section{Equivalência entre negócios e crime}

Force of Evil se inicia com uma tomada em plano geral do alto dos prédios de Wall Street, tendo, ao centro do enquadramento, o topo da Trinity Church. ${ }^{4}$ É possível ouvir, ao fundo, o badalar dos sinos da igreja, misturado ao tema musical de Force of Evil - iniciado ainda durante a abertura do filme - que diminui gradualmente de volume. A câmera desce em tilt $^{5}$ para mostrar o movimento dos carros na rua e das pessoas em passo apressado. Enquanto isso, escutamos em voz-over o narrador: "Essa é Wall Street. Hoje era um dia importante. Porque amanhã, 4 de julho, eu pretendia ganhar meu primeiro milhão de dólares. Um dia importante na vida de qualquer um".

A cena é filmada em plano geral sob a perspectiva do alto dos prédios de Wall Street. O narrador continua: “Temporariamente, o empreendimento era um pouco ilegal”. Há um fade-out $^{6}$ e a imagem da rua é substituída pelo hall de entrada de um dos prédios filmado em plano médio. ${ }^{7}$ Nesse momento, a câmera está posicionada dentro de uma banca de jornal. Desse ponto de vista temos, em primeiro plano, um jornaleiro e os seus clientes. Em segundo plano estão os elevadores do prédio. O movimento de pessoas no hall é intenso, e algumas delas param rapidamente diante da banca para fazer apostas. À direita da cena, aproxima-se um homem de terno e chapéu escuros, que começa a escolher jornais no balcão e é cumprimentado pelas outras pessoas, que se dirigem a ele como Sr. Morse.

Ao contrário dos outros clientes da banca, o Sr. Morse não faz apostas. Essas continuam sendo realizadas de maneira rápida e informal - o apostador somente entrega o valor ao jornaleiro, e diz o quanto quer apostar e em qual número, o que demonstra que a atividade é corriqueira.

Enquanto Morse escolhe os jornais que vai levar, dois homens conversam sobre a loteria. É possível observar que os protagonistas do diálogo em questão trajam o mesmo uniforme, levando o espectador a crer que são trabalhadores do próprio prédio em que se encontram. Há uma diferença evidente entre o uniforme que vestem e o terno de Morse. "Que tal isso, Bob?", pergunta um deles. Há um corte para um close de um jornal no qual se lê:

\footnotetext{
${ }^{4}$ Igreja localizada no sul da ilha de Manhattan de onde é possível ver o início de Wall Street.

5 Movimento de câmera para cima ou para baixo num deslocamento contínuo ao longo de um eixo vertical. (Cf. FRIEDMAN, A. Writing for Visual Media. Burlington: Focal Press, 2010, p. 64.)

${ }^{6}$ Uma transição visual entre tomadas ou cenas que aparecem na tela como um breve intervalo sem qualquer imagem. Geralmente utilizado para indicar uma mudança no tempo e no espaço (Cf. PANDEY, A. Academic Dictionary of Film, Television and Theatre. Delhi: Isha Books, 2005, p. 134).

7 "Situações em que, principalmente em interiores (uma sala, por exemplo), a câmera mostra o conjunto de elementos envolvidos na ação (figuras humanas e cenário)". (XAVIER, I. O discurso cinematográfico - a opacidade e a transparência. Rio de Janeiro: Paz e Terra, 1984, p. 19).
} 
"Número da sorte de hoje: 114". Novo corte, e o diálogo prossegue: "O número da sorte de hoje é 114. Apostei dez centavos no 113, não foi?”, ele pergunta. "Sim", uma voz responde em off. "Só não ganhei sessenta dólares por causa de um dígito. 600 para 1". "Vai apostar 776 amanhã?", Bob pergunta. "Não, 823. Hoje de manhã quase fui atropelado. Sabe qual era a placa? 823".

Nesse momento há um corte para um plano americano ${ }^{8}$ de Morse ajeitando os jornais. A voz do trabalhador continua em off. "Se depender de hoje, é meu número de sorte". Morse estica o braço para alcançar algo à frente dos dois apostadores. Aquele que estava falando toca o braço de Morse e pergunta-lhe: "Estou certo, Sr. Morse?". "Se ninguém te matar, é um dia de sorte para qualquer um”, ele responde, e todos na cena sorriem, enquanto Morse dirige-se a um dos elevadores do prédio. Outro apostador, também de uniforme, chega e faz uma aposta de cinco centavos no número 776.

Vemos um novo fade out e na cena seguinte há um plano médio do andar em que Morse desce do elevador. A câmera acompanha em pan shot ${ }^{9}$ os passos do protagonista, que se dirige a uma porta com uma placa colocada acima dela na qual está escrito "Wheelock and Morse". Enquanto isso, Morse explica os detalhes do jogo: “Os otários apostam em qualquer combinação de três números selecionados dos totais apostados em algum hipódromo aquele dia”. Nesse momento fica evidente que Morse é tanto o narrador quanto o protagonista da narrativa. Esse entra pela porta do escritório e passa rapidamente pela recepção e por mais uma sala até chegar à sua. No caminho, o protagonista cumprimenta os funcionários rapidamente. O narrador continua: "20 milhões de apostadores por dia nos Estados Unidos. A renda anual dos pequenos golpistas e apontadores dos jogos era de mais de 100 milhões de dólares". Quando Morse finalmente abre a porta de sua sala, ele finaliza: "Era uma pena que tanto dinheiro fosse parar no bolso dos outros".

A sequência de abertura do filme apresenta o uso de alguns procedimentos técnicos que chamam a nossa atenção. Em primeiro lugar, o tilt da cena inicial. Com um movimento de câmera que mostra do topo dos arranha-céus de Wall Street até a rua, temos uma metáfora visual do percurso de Joe Morse ao longo de Force of Evil. O protagonista inicia o filme planejando seu primeiro milhão de dólares em um escritório "nas nuvens" - como ele próprio define em uma conversa com seu irmão Leo - em contraposição com o final trágico do filme.

\footnotetext{
8 "Corresponde ao ponto de vista em que as figuras humanas são mostradas até a cintura aproximadamente, em função da maior proximidade da câmera em relação a ela" (Cf. XAVIER, I., op. cit., p. 19).

9 Também conhecido como panning, trata-se de um "movimento de câmera que explora o espaço cênico horizontalmente, movendo-se para a direita ou esquerda a fim de dar a impressão de uma cabeça virando para os lados, geralmente com o intuito de seguir algum objeto em movimento" (Cf. STADLER, J., MCWILLIAM, K., Screen Media: Analysing Film and Television. Crows Nest: Allen \& Unwin, 2009, p. 345 - tradução nossa).
} 
A presença da Trinity Church nessa primeira cena faz alusão ao tema religioso da narrativa de Force of Evil: a história bíblica de Caim e Abel que se estabelece na relação entre Joe e Leo. As nuances desse relacionamento conflituoso de irmão contra irmão - Leo sente inveja e ódio de Joe, embora haja uma preocupação fraternal entre os dois - são definidas na cena de reencontro dos irmãos, sobre a qual falaremos mais adiante. Por ora, vale notar que a Trinity Church reaparece outras vezes na narrativa, e que os enquadramentos dessas cenas aproximam visualmente a arquitetura gótica da igreja dos modernos arranha-céus de Wall Street. A proximidade entre esses dois universos - religioso e financeiro - em Force of Evil nos mostra que a narrativa bíblica, com a traição de Caim a Abel, encaixa-se perfeitamente ao contexto moderno do capitalismo.

Outro aspecto que também nos chama a atenção nessa sequência é a presença do narrador-protagonista, comum no cinema noir. Pela utilização dos tempos verbais, sabemos que o narrador de Force of Evil nos conta a história de um determinado ponto no futuro no qual os fatos já aconteceram. Em comum com outros filmes do período, temos o fato de que a narrativa de Force of Evil é enviesada pelo ponto de vista do narrador-protagonista. No entanto, ao contrário de Pacto de Sangue (Double Indemnity, Billy Wilder, 1944) e outros filmes do gênero, cujas narrações tratam de episódios particulares nas vidas dos protagonistas com alcance social restrito, em Force of Evil as ações do narrador-protagonista e seus associados têm consequências mais amplas nas vidas das pessoas - a começar pela conquista do monopólio do jogo de azar por Ben Tucker e a quebra da banca de seu irmão e de dezenas de outros proprietários. Force of Evil mostra que os efeitos dos negócios, legais ou não, afetam a sociedade como um todo.

O jogo de azar, por sinal, é mais um elemento da narrativa apresentado ao espectador nessa sequência inicial que merece ser avaliado mais detidamente. Polonsky opta por filmar a cena na banca de jornal em plano médio - um procedimento recorrente em vários momentos do filme -, o que insere os personagens num contexto específico e mostra a relação deles com as outras pessoas ao seu redor. Nesse caso, o que se nota na cena é uma diferença bem clara entre os apostadores e Morse. Enquanto os primeiros são trabalhadores braçais que vestem uniformes, o último é um advogado vestido com um terno bem alinhado.

Há, dessa maneira, uma associação apresentada desde o início do filme entre Wall Street, o negócio ilegal e o jogo. O primeiro é utilizado em Force of Evil como símbolo do capitalismo norte-americano, o sistema que, como o diretor nos mostrará ao longo do filme, não rege só a economia do país, mas também influencia as relações humanas. O segundo é 
consequência do crime organizado, que teve seu ápice nos Estados Unidos com o contrabando de bebida durante a Lei Seca nos anos 1920 e estruturou a forma mais lucrativa de se realizar negócios no país. Em terceiro lugar, o jogo introduz nessa associação uma relação entre o acaso e o capitalismo. De acordo com Ann Fabian, professora da Universidade Estadual de Nova Jérsei, na loteria estão "as promessas do capitalismo sem os seus processos" (FABIAN, 1999, p. 124), ou seja, a possibilidade do trabalhador mudar sua classe social repentinamente, sem que ele precise vender sua força de trabalho. No entanto, como o próprio filme nos mostra, até mesmo essa mobilidade social pode ser planejada, forçando o "acaso" a trabalhar em benefício do criminoso. Em última instância, podemos dizer que Tucker e Joe cometem um crime dentro de uma atividade ilegal. De acordo com Paul Buhle e Dave Wagner,

\begin{abstract}
Joe Morse explica a misteriosa ciência de acumular fortuna por meio das pequenas esperanças coletivas de otários que apostam tendo chances ínfimas, e por um breve momento o espectador se pergunta o que, afinal de contas, aquilo tem a ver com Wall Street, onde a nomenclatura de procedimentos financeiros é muito mais refinada. No entanto, logo se percebe que o conflito entre aparência e realidade é justamente a questão: esses pequenos criminosos, incluindo Joe, podem ter graduação em Direito em instituições de elite, vestir chapéus de seda, fumar cachimbos, e ter escritórios "nas nuvens", mas continuam sendo pequenos criminosos (BUHLE; WAGNER, 2001, p. 119).
\end{abstract}

Ao estabelecer as associações mencionadas no parágrafo acima, Force of Evil faz uma equivalência entre os negócios e o crime. Isso pode ser notado pela própria linguagem utilizada no filme, saturada de retórica corporativa. Fala-se o tempo todo em "bancos", “organizações”, “associações” e "fusões”. Além disso, na primeira vez em que Ben Tucker aparece em cena, vemos escrito na porta de seu cofre: “Tucker Enterprises Inc.". A organização de Tucker é descrita como uma grande corporação prestes a monopolizar o mercado e acabar com empreendedores independentes.

Um último aspecto importante dessa sequência inicial é a distinção que o narradorprotagonista faz entre si próprio e os apostadores do jogo. Morse chama-os de otários (“suckers"), uma vez que as chances de se ganhar no jogo eram ínfimas, e é justamente por meio das apostas desses otários e suas crenças em uma superstição ${ }^{10}$ que ele pretende fazer seu primeiro milhão de dólares. No entanto, esse tratamento se torna problemático quando sabemos, mais adiante, que Joe tem raízes bem mais humildes que sua atual condição de advogado de um grande escritório em Wall Street. Em última análise, seu comportamento pode ser considerado uma das muitas traições presentes no filme - nesse caso específico, de

\footnotetext{
${ }^{10}$ De acordo com o filme, há uma superstição de que o número 776 seja o "número da sorte" no feriado do dia 4 de julho 1776 é o ano da Declaração de Independência dos Estados Unidos.
} 
classe. Polonsky problematiza ainda mais essa questão ao estabelecer uma relação complexa entre Morse e seu irmão Leo. A descrição e a análise das cenas abaixo tratarão dessa questão.

\section{A relação entre Joe e Leo}

Depois de encontrar Ben Tucker e conversar com ele sobre a situação de Leo - que poderia enfartar caso sua banca quebrasse com o golpe planejado pelo gângster -, Joe vai até a banca de apostas de seu irmão para tentar convencê-lo a entrar em sociedade com Tucker. A sequência desse reencontro se inicia com Joe chegando de carro a um cenário bem diferente de Wall Street. Na primeira cena, vemos uma tomada em plano geral da rua, vista de uma das calçadas. A câmera mostra em primeiro plano um homem abrindo uma garrafa de refrigerante. Mais adiante na narrativa, esse mesmo personagem se apresentará para Bauer (Howland Chamberlain) - o contador de Leo Morse - como Wally (Stanley Prager), funcionário de Bill Ficco (Paul Fix), concorrente de Tucker nos tempos de contrabando de bebida. Na calçada vemos um pequeno poste indicando um ponto de ônibus, além de uma caixa do correio.

A cena se inicia com o carro de Joe parando próximo ao ponto de ônibus; ouve-se ao fundo a trilha sonora evocando um clima de mistério; Joe desce e dispensa o motorista, enquanto confere o endereço num pedaço de papel que tem no bolso. Wally deixa a garrafa sobre uma geladeira e se aproxima de Joe. Há um corte, a trilha sonora diminui o volume e vemos, em plano americano, Wally, de costas para a câmera, pedindo fósforos emprestados para Joe. Esse último tira os fósforos do bolso, entrega a Wally e diz: "Pode ficar com eles". A câmera permanece fixa com Wally em primeiro plano, que acende um cigarro e observa Joe atravessar a rua.

Antes de entrar por uma porta, o narrador-protagonista começa a explicar as atividades de Leo: "Há anos não via meu irmão Leo. E aqui estava ele, de volta ao cortiço onde nascemos". Nesse momento há um corte, e vemos Joe subindo uma escada. Continuamos ouvindo ao fundo a trilha sonora misturada ao barulho de máquinas e de moedas.

Ao chegar à porta do apartamento da banca de Leo, Joe é atendido por Bauer primeiramente por uma fresta na porta. Assim que Joe entra, vemos um plano geral do interior do recinto, e o ruído das máquinas e moedas aumenta. Embora a visita seja feita durante o dia, todas as janelas estão cobertas por persianas, a fim de evitar que se observe de fora o que 
acontece no apartamento. O ambiente, dessa forma, é escuro, iluminado apenas por alguns lustres que descem do teto. A profundidade de campo nos permite observar com nitidez, além de Joe, outras onze pessoas em cena, entre homens e mulheres. Joe aparece no quadro em segundo plano, à esquerda. Em primeiro plano estão dois funcionários separando moedas em sacos com uma máquina e outro trabalhando numa máquina de calcular. Ao fundo, é possível ver, enquadrada por uma pequena janela, a secretária de Leo, Doris Lowry (Beatrice Pearson), sentada em outra sala enquanto atende um cliente. A voz do narrador, então, se sobrepõe ao ruído do ambiente: "As bancas ficavam atrás de salas de bilhar, armazéns, adegas ou escondidas nos apartamentos de cortiços, como o do Leo".

Figura 1 - A banca de Leo Morse

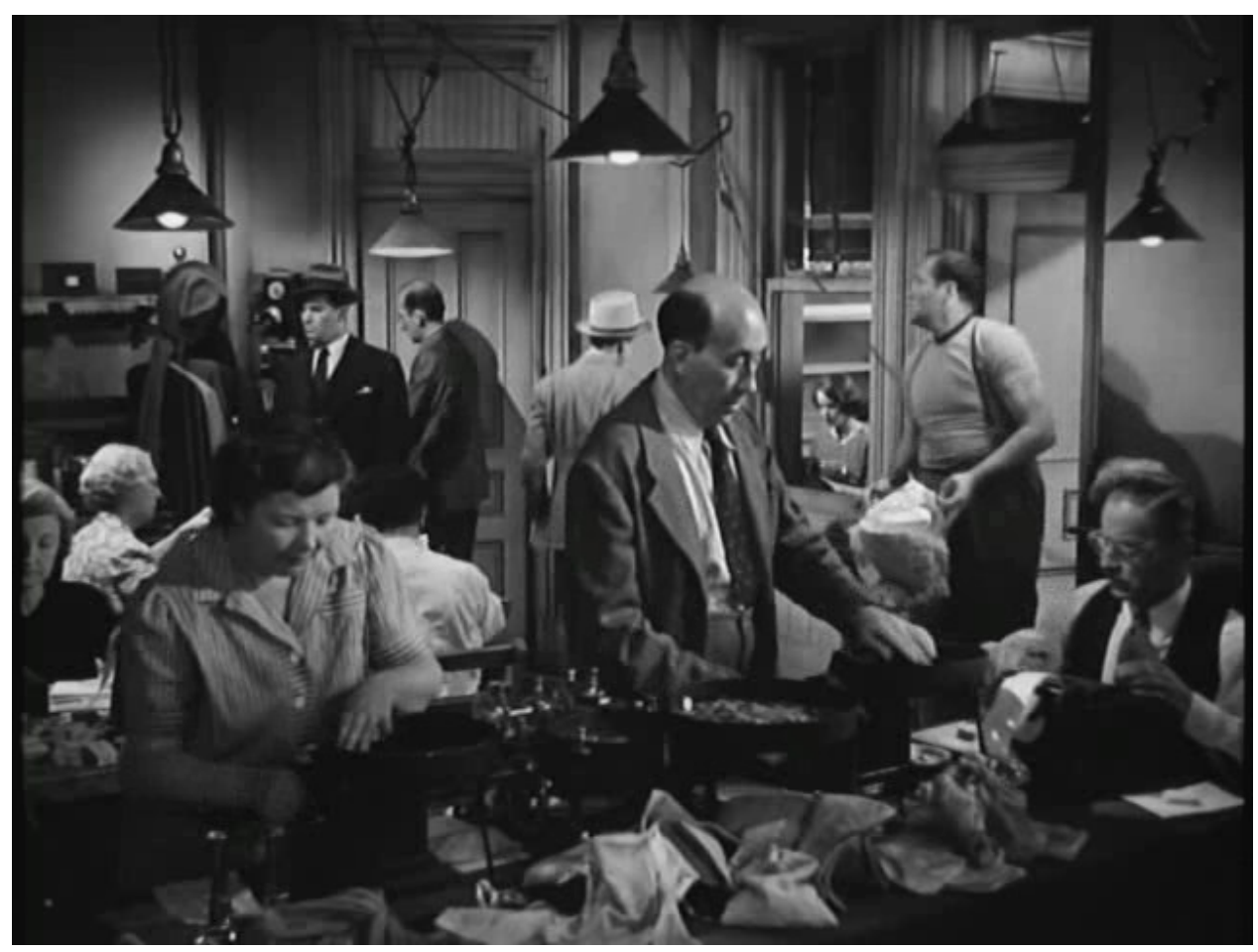

Fonte: (FORÇA do Mal, 2007)

Após um corte, o diretor nos mostra um plano de detalhe dos instrumentos de trabalho dos funcionários de Leo - a máquina de calcular e a que separa as moedas. Em vozover um dos funcionários diz: "Grande aposta no 776 hoje". Temos um corte e vemos um plano médio enquadrando Joe, o cliente da banca, Bauer, um dos funcionários sentado à mesa de costas e Doris sentada ao fundo. O cliente da banca vira-se para o funcionário e diz: "As pessoas têm a superstição de jogar todo 4 de julho. O velho número da liberdade. Nunca sai”. Enquanto o cliente conversa com o funcionário, Joe começa a se dirigir à sala de Leo. Doris, que até o momento não havia percebido a presença de Joe, imediatamente é atraída por ele, e 
o olhar dela acompanha os passos de Joe pelo corredor, ignorando o cliente que tenta falar com a secretária.

Figura 2 - Doris observa Joe e ignora o cliente

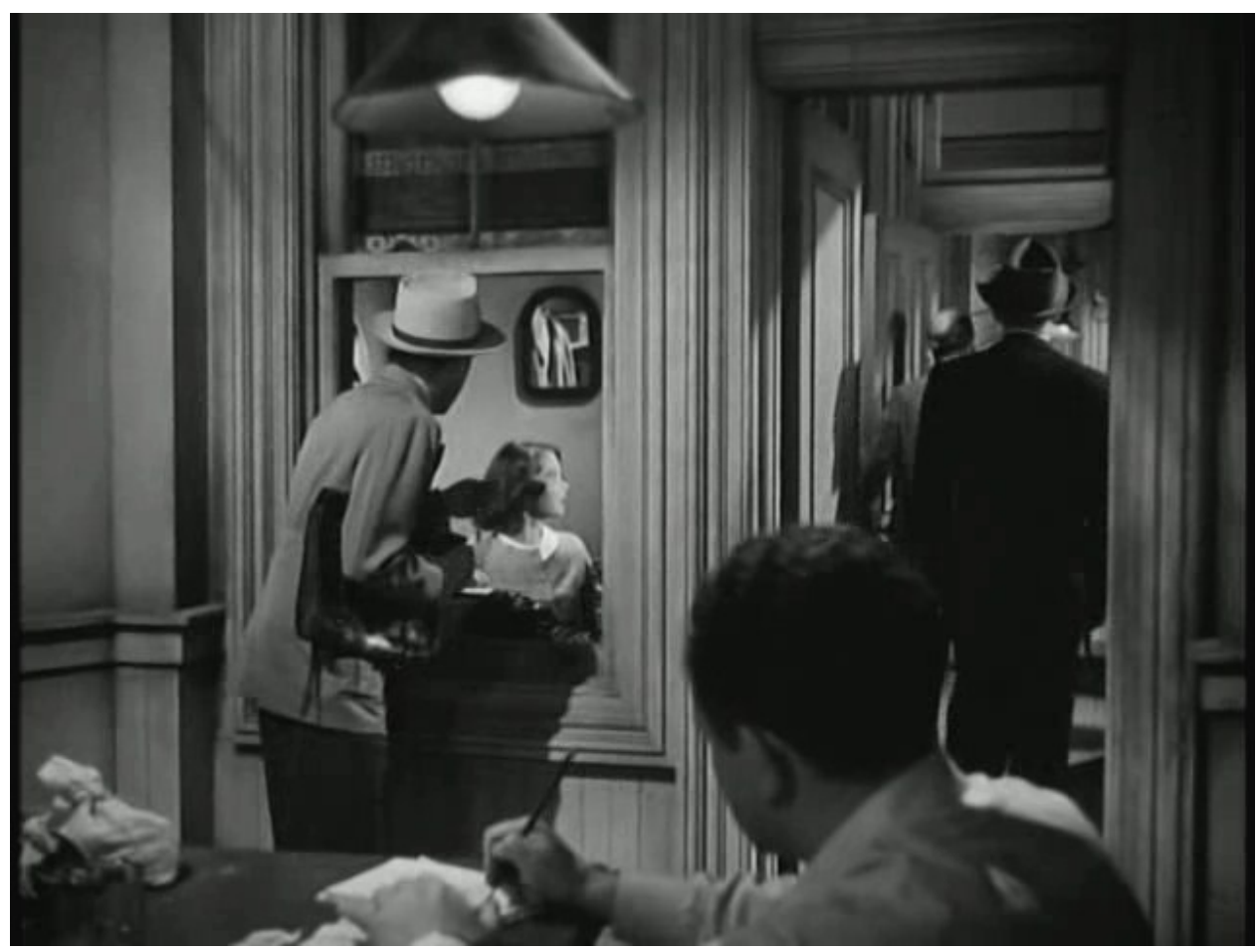

Fonte: (FORÇA do Mal, 2007)

Antes de seguir para a banca de Leo, Joe se encontra com o gângster Ben Tucker e, durante a conversa, justifica trabalhar para ele por dois motivos: o primeiro seria o enriquecimento que o empreendimento traria ao advogado; o segundo seria proteger Leo, que tem problemas de saúde. O protagonista demonstra estar preocupado com seu irmão, uma vez que esse poderia morrer caso falisse junto com as outras bancas por causa do esquema engendrado por Tucker e pelo próprio Joe. Entretanto, o início da sequência que marca o reencontro dos irmãos demonstra uma ambiguidade de caráter do protagonista. Embora sua preocupação fraternal pareça autêntica, o narrador nos revela que "não vê seu irmão há anos", o que deixa claro que sua visita só foi feita porque era extremamente necessária.

O diretor também nos apresenta, na cena inicial dessa sequência, Wally, um personagem cujo nome só nos será apresentado mais adiante no filme. Wally aparece de maneira ainda mais discreta diversas vezes durante a narrativa nas mais variadas situações, como um observador dos acontecimentos que reforça a onipresença do crime organizado em Force of Evil. Ao nos apresentar esse personagem dessa maneira e colocá-lo em cena de forma discreta em outros momentos do filme, Polonsky também propõe ao espectador que ele 
esteja atento tanto às ações centrais da cena, praticadas pelos protagonistas, quanto às periféricas ou que ocorrem em segundo plano, uma vez que todas têm a sua devida importância dentro da narrativa e ajudam a entendê-la. Esse procedimento é recorrente no filme, e pode ser realizado de diversas maneiras: por meio da montagem, da escolha de um determinado enquadramento ou movimento de câmera, e também pela direção dos atores. A cena em que Doris acompanha os passos de Joe é um bom exemplo desse recurso.

No momento em que Joe entra pela porta do apartamento, Polonsky nos apresenta o primeiro aposento em um plano geral em câmera estática (Figura 1). O acompanhamento da sequência de planos que mostram Joe chegando ao bairro e subindo as escadas do prédio faz com que o espectador concentre sua atenção no protagonista. No entanto, nesse plano geral em questão, embora a quantidade de informações apresentada de uma só vez seja grande, o espectador é convidado a estabelecer relações entre os elementos apresentados, pois o tempo em que o mesmo enquadramento permanece na tela ajuda o espectador a absorver todas as informações sem problemas. O que primeiro nos chama a atenção no quadro é a informalidade do trabalho: a organização é precária e há muitas pessoas trabalhando em diferentes atividades num ambiente relativamente pequeno. As máquinas de contar moedas cujo ruído acompanha a cena o tempo todo, mesmo quando a voz do narrador a sobrepõe são manuais e operadas por um homem e uma mulher. A mais jovem do grupo é Doris, que aparece na cena em segundo plano.

O tempo que Polonsky dedica a essa cena e a descrição feita pelo narrador destacam o processo do trabalho, mesmo que clandestino. Esse procedimento fica ainda mais evidente quando, na cena seguinte, o diretor nos mostra um plano de detalhe de duas ferramentas de trabalho essenciais dos funcionários de Leo: a máquina de calcular e a de contar moedas. Tal registro de grupos de trabalhadores em seu ambiente de trabalho coletivo leva, em Force of Evil, a uma reflexão incomum dentro do cinema hollywoodiano sobre os processos produtivos. Enquanto a maioria dos filmes norte-americanos procura concentrar a narrativa somente em seus protagonistas, Force of Evil direciona o olhar dos espectadores nessa cena para os trabalhadores e chama a atenção para o fato de que eles estão envolvidos de alguma forma na narrativa.

Vale notar a presença do dinheiro nessa e em outras sequências desde o início do filme: ele está no discurso do narrador na cena de abertura, nas mãos dos apostadores na banca de jornal, no cofre que Joe abre dentro de seu escritório, nas mãos de Tucker e, agora, nos instrumentos de trabalho dos funcionários de Leo. A diferença entre uma referência e 
outra ao dinheiro é justamente a quantidade: enquanto Leo e Tucker conversam em termos de milhões de dólares, os trabalhadores só lidam com centavos.

Por último, chama-nos a atenção nesse trecho descrito o interesse de Doris por Joe. Há várias ações concomitantes na cena: o cliente da banca conversa com um dos funcionários, comentando sobre a superstição com o número 776; ao fundo, Bauer abre a porta da sala de Leo; Joe, por sua vez, anda em direção a Bauer; enquanto isso, o ruído das moedas permanece constante. Mesmo com todas essas distrações visuais e sonoras para o espectador - e embora seja possível ver Doris somente do busto para cima através de uma janela -, a duração prolongada do plano e a profundidade de campo da cena nos permite acompanhar todas as ações simultâneas e perceber o movimento de Doris, que não é nada discreto (Figura 2). A atração de Doris por Joe é um dado importante para o espectador porque, a partir dele, é possível compreender melhor as ações da personagem ao longo da narrativa. Poderemos observar outras atitudes de Doris no prosseguimento da nossa descrição.

Bauer anuncia a Leo que seu irmão quer vê-lo. Há um corte e vemos Leo pela primeira vez, em um plano médio de seu escritório. O personagem está sentado à sua mesa em um canto da sala, mastigando um sanduíche enquanto trabalha. A mesa é rústica e o seu material de trabalho se mistura aos guardanapos. Leo é gordo e tem o cabelo desgrenhado; ele veste camisa branca, colete e uma gravata no colarinho mal engomado. O ambiente é ainda mais escuro que os outros do escritório - somente um lustre ilumina a mesa de Leo. "Meu irmão?", pergunta Leo, estranhando a presença de Joe no escritório. "Como ele é?". "Como fogos de artifício, seu bobo", Joe responde, de maneira jocosa, entrando na sala e fechando a porta atrás de si, deixando Bauer para fora. A câmera o mostra em plano médio, destacando seu sorriso e a elegância de seu terno escuro. Joe se aproxima de Leo, joga o chapéu sobre a mesa e senta-se de maneira desleixada sobre ela. Tem início então o diálogo entre os dois mostrado em campo e contracampo e em planos médios dos dois personagens:

Joe: Como vai, Leo?

Leo: O que você quer, Joe?

Joe: Vim te ver, Leo. Preciso de um motivo especial?

Leo: Não viria aqui se não tivesse motivo especial.

Joe: Que diferença faz? Somos irmãos.

Leo [para de trabalhar e olha para Joe]: É visita social ou de negócios? Não te vejo há séculos. [impaciente] O que é, estou ocupado.

Joe: Leo... [faz uma pequena pausa e levanta-se da mesa] Vou te tirar dessa espelunca e te colocar num escritório de verdade, com negócios de verdade. Para retribuir por tudo, porque você é meu irmão mais velho. Por isso eu vim.

Leo [pega um lenço amarrotado e seca o suor do rosto]: Volte quando eu estiver morto. 
Joe [aumentando o tom de voz]: Briguei para chegar nessa proposta, arrisquei o pescoço. [De maneira ríspida] Agora escute! Algo muito sério vai acontecer com seu negócio. A sua é uma das 20 ou 30 bancas da cidade. Uma das menores. [começa a caminhar para perto das janelas com as mãos na cintura - a câmera mostra o rosto de Leo em primeiro plano à direita e Joe à esquerda, ao fundo] Suponha que uma sociedade apareça. Suponha que ela organize e mescle essas bancas, eliminando as menores como a sua. Agora está me escutando, não é? [Joe começa a se aproximar de Leo, apoiando os braços na mesa] Suponha que reduzam gastos gerais, legais, fianças, diminuindo os custos para garantir os lucros. Um homem como você estaria fora do ramo. Não poderia competir, certo? Mas suponha que você tem um irmão. Que faz sua banca ser a primeira na fusão, na companhia, na corporação.

Leo: Qual corporação? Tucker? [alguém bate à porta] Entre!

Nesse instante, Doris abre a porta e entra na sala segurando um copo de leite e alguns bilhetes. Ela primeiro sorri e acena discretamente com a cabeça para Leo, mas logo em seguida volta seus olhos para Joe. "Estou com os bilhetes ganhadores, Sr. Morse", ela diz, enquanto se aproxima da mesa e deixa o copo e os bilhetes sobre ela - sem tirar os olhos de Joe, que não demonstra qualquer interesse em Doris. O diálogo entre Joe e Leo prossegue, enquanto Doris se dirige a um cofre no chão, próximo à parede.

Leo: E o que essa corporação espera de mim, irmão Joe? Leo: Em troca da organização... [Joe hesita e olha para Doris] Joe: Não guardo segredos da Doris. Se quiser falar, fale. Ou saia.

Joe: Em troca da organização dos serviços e em troca da sua entrada, ela fica com dois terços dos lucros e você com um terço. Por outro lado...

Leo [interrompendo Joe]: Dois terços pro Tucker, irmão Joe, e um terço pro meu negócio? [Joe se afasta da mesa] Sabe o que é isso, Joe? [levantando a voz] Chantagem! [Joe e Doris viram-se assustados para Leo] Isso que é, chantagem! [dirigindo-se a Doris] Meu próprio irmão me chantageando!

Joe [andando de volta para a mesa e batendo com a mão nela]: Está louco! Totalmente louco! Não está me escutando!

Leo: Não quero!

Joe: Sabe por que não quer? Digo por que: porque é um homem pequeno! Para as coisas pequenas você é um tigre. Um tigre! [Leo, transtornado, coloca a mão no peito e toma um gole do copo de leite] Mas se é algo grande você grita, esperneia e xinga. [De maneira jocosa] "Oh, não, um milhão de dólares para o Leo? Deve ser endereço errado, deve ser para o vizinho."

Leo [levantando-se da mesa, dirigindo-se à porta; ao mesmo tempo, Doris também se levanta com alguns maços de dinheiro na mão e para ao lado de Joe]: A resposta é não!

Joe: Você entende que a sua resposta não impede a fusão das bancas, inclusive a sua? [Leo está prestes a abrir a porta, mas Joe o interrompe, pegando em seu braço] Leo, está é sua chance. Eu a consegui pra você.

Leo: Pegue sua chance, Joe, e saia daqui. Sou um homem honesto e não um gângster como o Tucker!

Nesse momento, Leo abre a porta da sala e volta para sua mesa. A câmera filma em plano médio Joe em pé, parado, observando Leo que já saiu do enquadramento. Em segundo plano, ao fundo, a porta aberta revela quatro funcionários de Joe acompanhando o que acontece na sala de Leo. 
Figura 3 - Os funcionários de Leo acompanham a discussão

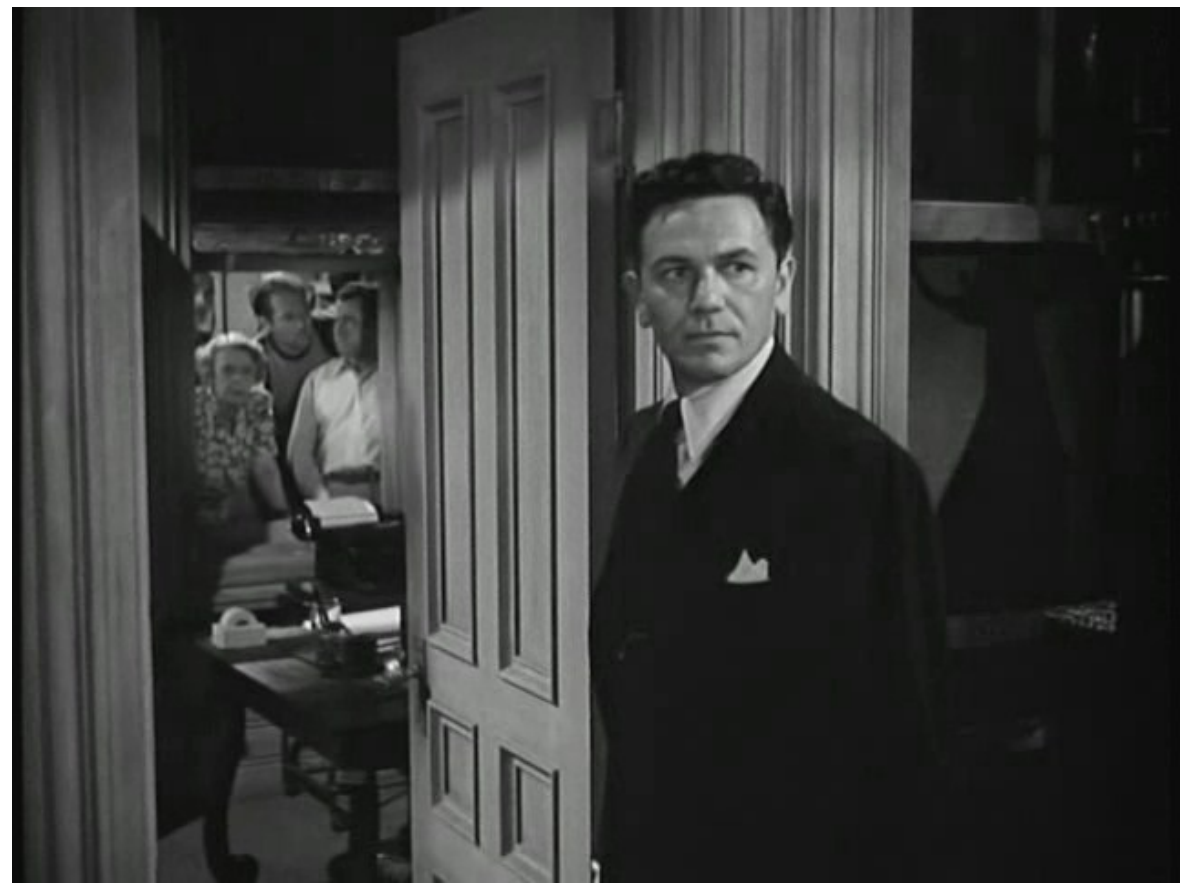

Fonte: (FORÇA do Mal, 2007)

Joe olha para a direita do enquadramento na direção de Leo e pergunta: "Está dizendo para mim, um advogado corporativo, que você tem um negócio legal aqui?". Joe volta-se para os funcionários ao fundo, fecha a porta e continua a discussão, de maneira ríspida: "Do que chama isso? Pagamentos por jogatina, esquema de apostas ilegais? Violação do artigo 974 do código penal. Jogo de azar!”. Há um corte e vemos Leo atrás da mesa com Doris ao seu lado, segurando os maços de dinheiro no peito, olhando assustada para Joe. "Faço meus negócios honesta e respeitosamente." Com outro corte, o diretor nos mostra Joe, acompanhando-o em pan shot em direção aos dois, até enquadrar os três personagens novamente em plano médio. 
Figura 4 - Joe, Doris e Leo

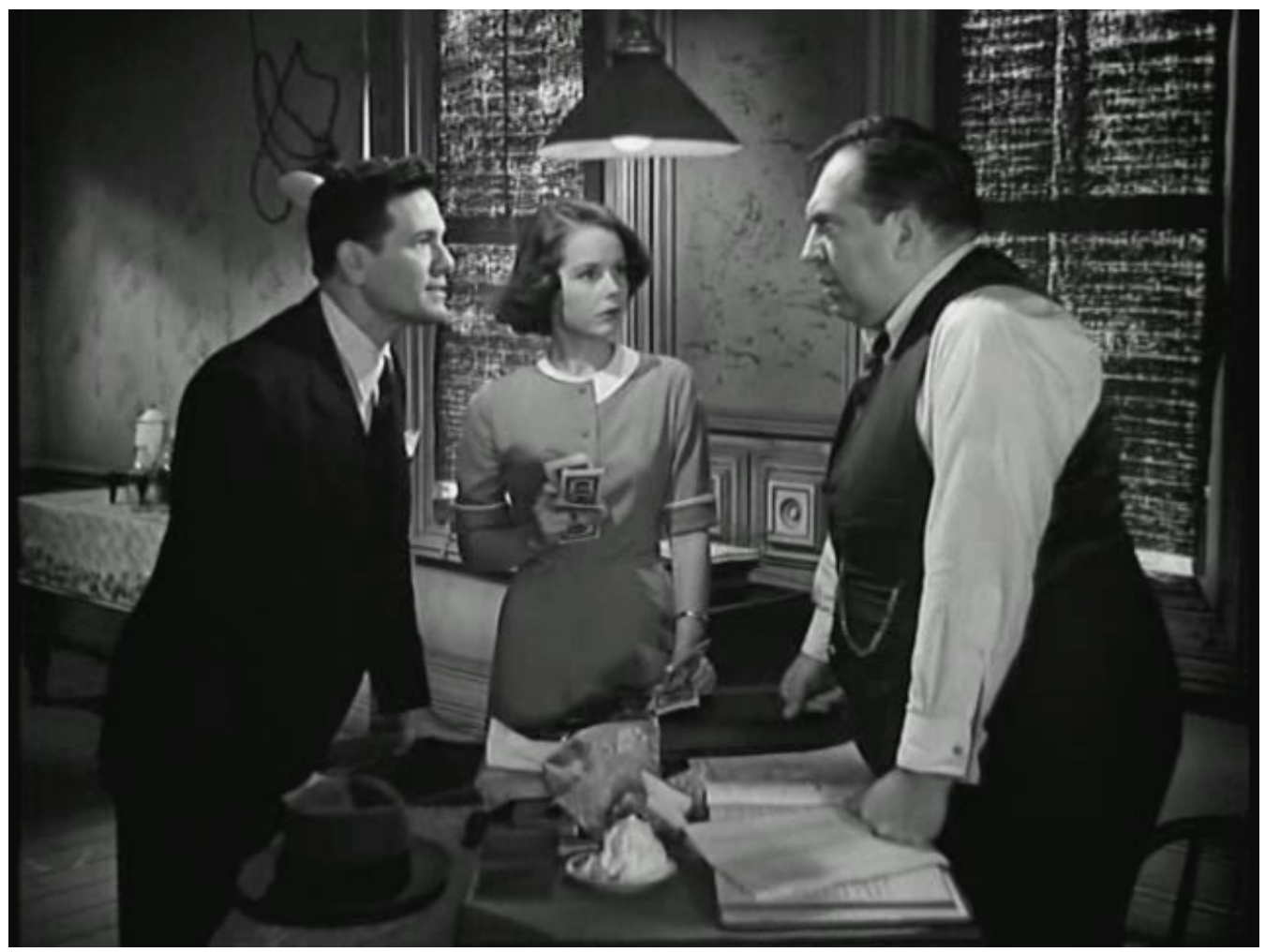

Fonte: (FORÇA do Mal, 2007)

Enquanto caminha, Joe diz, de maneira irônica:

Joe: Honesta e respeitável? [apoia as mãos sobre a mesa; Doris olha para Leo incrédula] Você não pega os cinco, dez centavos de apostadores como qualquer safado, grande ou pequeno, nesse esquema? Chamam isso de "apólice" porque jogam os centavos no jogo em vez de gastar em algo importante como apólice de seguros. É por isso! Tucker quer fazer milhões, você quer fazer milhares e você [dirige-se a Doris; ela olha, assustada] faz por 35 dólares por semana [Doris larga o dinheiro sobre a mesa, envergonhada]. Tudo a mesma coisa.

Leo: Essa é minha secretária, minha estenógrafa. [Doris, hesitante, sai de perto da mesa e volta para o cofre] Minha amiga Doris Lowry! Está comigo há muito tempo e é como uma filha para mim. E você... Eu queria ser advogado e poderia ter sido, se tivesse te mandado pra rua quando nossos pais morreram. Mas não... Trabalhei como um idiota! Por você! Te dei tudo!

Joe: Por que fala assim comigo na frente de estranhos?

Leo [exaltado]: Ela não é estranha! O estranho é você! [saindo da mesa, indo pegar seu paletó ao lado da porta; a câmera o acompanha em pan shot] E vou dizer a todo mundo porque é meu irmão. Devo isso ao mundo pelo que você é. Um safado, um enganador e um gângster!

Joe [indo em direção a Leo, que está de costas]: Leo, se acalme... Tucker vai te fazer honesto e respeitável. Ele está me dando 250 mil para legalizarmos o jogo de uma vez, como o bingo, a loteria irlandesa. Vou te pagar de volta, Leo. Vou te fazer rico. Com um escritório em Wall Street, lá nas nuvens! [Joe ajuda Leo a vestir o paletó] Acalme-se, Leo. Seja razoável.

Leo [exaltado, virando-se pra Joe, que permanece impassível]: Tudo bem! Eu sou razoável. Estou calmo. Dou-lhe minha resposta final e sensata: Minha resposta final é finalmente "não". Absolutamente e finalmente não! Positivamente não! [gritando] Não, não, não! E não! [sai pela porta] 
Essa sequência de reencontro de Joe e Leo estabelece para o espectador, além das diferenças entre os irmãos, o tipo de relacionamento que existe entre os dois, e problematiza tal relação em vários níveis. O que se nota primeiramente é que, embora se porte com desenvoltura no escritório de seu irmão, Joe não pertence àquele ambiente - bem diferente do seu escritório em Wall Street. A precariedade das instalações da sala de Leo formam um contraste com o escritório de Joe, que possui uma grande mesa de madeira trabalhada, além de bancos e sofás revestidos de couro e quadros pendurados na parede.

Em segundo lugar, a recepção nada amigável de Leo revela um conflito posto de antemão. "É visita social ou de negócios?", ele pergunta, e estabelece logo no início da conversa uma antítese entre negócios e as relações pessoais. Leo sabe que não há qualquer possibilidade de coexistência harmônica entre esses dois universos e não espera de Joe qualquer tipo de atitude fraternal - nem como irmãos de sangue e muito menos como irmãos de classe. Joe, por sua vez, antes mesmo de apresentar sua proposta, justifica sua ação pelos laços familiares. O espectador sabe, pelo diálogo anterior dele com Tucker, que o remorso de ver seu irmão arruinado - morto, talvez - devido a uma ação planejada sua é o que o faz ir até o escritório de Leo. Estabelece-se, dessa maneira, uma relação incongruente entre dinheiro e família que é explorada ao longo do filme.

A conversa entre os irmãos é interrompida por Doris momentos antes de Joe apresentar os termos da oferta de Tucker a Leo. Doris vê Leo acusar Joe de chantagem, recusar a proposta e exaltar a própria honestidade, além de chamar seu irmão de gângster. De acordo com o professor Jack Shadoian,

\footnotetext{
ambos [Joe e Leo] são corruptos, embora Leo afirme ter seus valores morais, que são progressivamente minados com o decorrer do filme. Eles se amam como irmãos e cada um insiste que aquilo que fizeram ou fazem é em benefício do outro. $\mathrm{O}$ conflito prossegue, filosófica e emocionalmente. Joe busca aliviar sua culpa tentando fazer com que Leo enriqueça. As recusas insistentes de Leo têm um toque de perversidade. Ele também é culpado, invejoso. Em última instância, ele é mais cego que Joe, e não é mais moralmente correto que seu irmão (SHADOIAN, 2003, p. 121).
}

A figura 3 mostra os funcionários de Leo, que haviam parado de trabalhar e acompanham atentamente a discussão. A escolha do enquadramento e a profundidade de campo permitiram ao diretor mostrar tanto a ação principal, com Joe em primeiro plano, como os trabalhadores em segundo plano, emoldurados pela porta e pela janela. Joe fecha a porta para isolá-los da conversa, assim como fez com o engraxate Louie quando precisava de privacidade ao conversar com Hobe, seu sócio no escritório de advocacia. Essas atitudes de 
Joe estabelecem um limite bem definido entre os trabalhadores braçais e ele próprio quando se trata de negócios. A única com quem Joe estabelecerá alguma relação é Doris, mas os interesses nesse caso serão amorosos.

Leo afirma a Joe que mantém seus negócios de maneira "honesta e respeitável". Em última instância, o primeiro "afirma com convicção, embora de maneira irracional, que ladrões menores são mais honestos que os grandes" (BUHLE e WAGNER, 2001, p. 120). A figura 4 mostra o momento em que Joe começa a argumentar com seu irmão, revelando a Doris uma realidade sobre o trabalho com o jogo de azar que ela, a julgar pela sua reação, não tinha consciência. O plano médio registra visualmente posições que se confrontam e se debatem, mesmo estando ambas no âmbito da ilegalidade. Para Shadoian,

eles [Joe e Leo] não conseguem enxergar que fazem as mesmas coisas, são unidos tanto pelo amor quanto pela corrupção. E não conseguem enxergar porque, seguindo os caminhos do mundo, suas naturezas e seus verdadeiros conhecimentos das coisas foram deformados. Polonsky está falando sobre o que viver no sistema econômico americano faz com as pessoas, Leo e Joe e todos os outros (SHADOIAN, 2003, p. 121)

Ainda na figura 4 é possível ver Doris, ao centro, com os maços de dólares nas mãos, confusa a respeito de qual lado da mesa deve ficar. Quando Joe revela a Doris que ela também faz parte de um negócio ilegal, ela larga o dinheiro, num gesto de repúdio ao que ele representa. Joe demonstra um nível de racionalidade e clareza que confude Doris. Leo traz à tona sua mágoa com Joe, diz a ele que Doris é muito mais da sua família do que o próprio irmão e rejeita veementemente a proposta de Tucker.

Essa sequência, além de ser fundamental para o entendimento da relação complexa entre Joe e Leo, também nos serve como modelo para o tipo de relacionamento que se estabelece entre outros personagens. Em Force of Evil, a vida social é vista como um conflito generalizado, uma vez que há traições em todos os níveis: Joe trai Leo em nome do dinheiro; Leo também é traído por Bauer, seu funcionário, que o entrega para o gângster Joe Ficco; Ficco, por sua vez, assassina Leo e rompe o acordo feito previamente com Ben Tucker; esse último é traído por Edna, sua esposa, que tenta seduzir Joe; o advogado também trai Tucker ao fazer com que a conversa entre eles, na qual o gângster revela todo o esquema ilegal da fusão das bancas, seja ouvida pela polícia por meio do grampo telefônico autorizado pelo promotor Hall.

Tal conflito também se dá no âmbito dos princípios individuais, no caso de Leo. Em outro momento da narrativa, após a falência das bancas - incluindo a de Leo - com o número 
776 saindo na loteria, Joe vai até a casa de Leo para "limpar sua consciência" e tentar convencê-lo novamente a aceitar a oferta de Tucker. Sylvia, esposa de Leo, não quer que ele ouça qualquer proposta de Joe, pois, de acordo com ela, Joe é um ladrão, e "conselho de ladrão nunca é bom":

Sylvia: Não se envolva com ele, Leo. Você é um homem de negócios.

Leo: Sim, fui um homem de negócios minha vida inteira e, honestamente, eu não sei o que é um negócio.

Sylvia: Bem, você teve uma oficina mecânica, você teve uma imobiliária.

Leo: Você acha que sabe alguma coisa. Sim, uma imobiliária. Vivendo de hipoteca em hipoteca, roubando crédito como um ladrão. E a oficina - aquilo era um negócio! Três centavos a mais para cada galão de gasolina, dois para o chofer, e um centavo para mim. Um centavo para um ladrão, dois centavos para o outro. Agora com Joe aqui não vou mais precisar roubar centavos. Vou ter grandes bandidos pra roubar dólares pra mim.

Além do diálogo de Leo com Sylvia servir para reforçar a linha tênue que separa os negócios legais dos ilegais - tema do filme desde o seu início -, ele também nos revela que, se antes Leo acreditava ter uma determinada correção moral que o colocava acima de Joe, a visita do irmão o fez rever seus conceitos e desfazer as ilusões de honestidade nos seus negócios. Para Buhle e Wagner, o mundo apresentado por Polonsky em Force of Evil é diferente de qualquer outro visto em Hollywood, pois "existem somente ilusões e desilusões para uma população enfraquecida, e qualquer um que tente estabelecer distinções morais cai em desespero profundo" (BUHLE; WAGNER, 2001, p. 119).

\section{A morte de Leo}

Depois de ser forçado a participar do processo de fusão das bancas de jogo, Leo é traído por Bauer, que o leva para uma emboscada armada pelos capangas de Joe Ficco. Nessa armadilha, Leo é sequestrado, Bauer é assassinado e as notícias chegam até Joe, que vai até o escritório de Tucker a fim de descobrir o que estava acontecendo. Nesse momento, o advogado encontra Ficco e Tucker firmando um acordo. Ao perguntar sobre seu irmão, Joe fica sabendo por meio de Ficco que Leo está morto e seu corpo fora jogado no leito do rio Hudson. Joe, então, discretamente tira o telefone grampeado de Tucker do gancho e faz com que toda a conversa seja ouvida pela polícia. Tucker percebe a traição e inicia-se um tiroteio, do qual somente Joe sobrevive. O advogado resolve, então, procurar o corpo de Leo no rio antes de se entregar para a polícia. Nesse momento, Joe diz, em voz-over, de forma grave e pausada: 
Joe [voz-over]: Doris estava me esperando lá embaixo. Saímos antes da polícia chegar. Queria achar Leo, vê-lo uma vez mais. Estava amanhecendo, e naturalmente me sentia muito mal ali. Segui descendo... Mais e mais... Como se descesse ao fundo do poço... Para encontrar meu irmão.

Enquanto Joe narra o desfecho da narrativa, a música-tema do filme serve como fundo sonoro e o diretor nos mostra dez tomadas diferentes de escadas, ladeiras e muros pelos quais Joe tem que passar para chegar até o leito do rio. A descida de Joe até o "fundo do poço" forma uma rima visual com a cena de abertura do filme, conforme já comentamos anteriormente, e resume o percurso do protagonista na narrativa.

Assim que Joe encontra Leo, o narrador finaliza:

Joe [voz-over]: E encontrei o corpo de meu irmão lá no fundo. Eles o haviam jogado nas rochas, junto ao rio. Um trapo velho e sujo que ninguém quer. Estava morto. $\mathrm{E}$ senti que eu o havia matado. Voltei para me entregar a Hall porque se a vida de um homem pode ser vivida por tanto tempo e acabar assim como lixo então algo estava errado. E devia terminar, de um jeito ou de outro. Então decidi ajudar.

De acordo com os críticos Buhle e Wagner,

\begin{abstract}
todas as linhas do enredo levam à mesma conclusão: a culpa de Joe sobre sua traição e como ela começa a ditar todas as suas ações. Nós sabemos que em algum ponto ele deve se reconciliar com Leo, não somente como um homem de negócios corrupto que quer dividir seu lucro, mas em um sentido mais amplo. O filme não dá indícios de como essa reconciliação poderia acontecer, e em um mundo tão corrupto tal ato pode nem ser possível (BUHLE; WAGNER, 2001, p. 121).
\end{abstract}

Por mais que a narrativa aponte o processo de aprendizado do protagonista e o final reestabeleça a ordem por meio do arrependimento e da punição de Joe, tal reconciliação, como pudemos observar, não ocorre. O que Force of Evil nos dá a entender é que a corrupção é resultado da "força maligna" - presente até mesmo no título do filme - e irracional do capitalismo, que dita a instabilidade das relações humanas e provoca o conflito familiar entre os irmãos Morse. Por meio do comportamento de Joe em relação a seus antigos irmãos de classe e sua traição a Leo, Polonsky nos mostra que, enquanto não houver uma mudança radical na política e na economia norte-americanas, as divisões intra-classe continuarão a existir e o poder destrutivo do capitalismo perdurará. Dessa forma, qualquer tipo de reconciliação mais ampla continuará cada vez mais longe no horizonte. 


\section{Referências}

BUHLE, P., WAGNER, D. "The politics and mythology of film art: Polonsky's noir era". In: A very dangerous citizen: Abraham Polonsky and the Hollywood Left. Berkeley and Los Angeles: University of California Press, 2001.

DENNING, M. The Cultural Front: The Laboring of American Culture in the American Century. New York: Verso, 1996.

FABIAN, A. Card sharps and bucket shops: gambling in nineteenth-century America. New York: Routledge, 1999.

FORÇA do Mal. Direção: Abraham Polonsky. Fortaleza: Classic Line, 2007. 1 DVD (78 min), NTSC, P\&B. Título original: Force of Evil.

FRIEDMAN, A. Writing for Visual Media. Burlington: Focal Press, 2010.

MUNBY, J. Public Enemies, Public Heroes - Screening the Gangster from Little Caesar to Touch of Evil. Chicago: The University of Chicago Press, 1999, p. 124.

PANDEY, A. Academic Dictionary of Film, Television and Theatre. Delhi: Isha Books, 2005.

SHADOIAN, J. Dreams and Dead Ends: The american gangster film. New York: Oxford University Press, 2003.

STADLER, J., MCWILliAM, K., Screen Media: Analysing Film and Television. Crows Nest: Allen \& Unwin, 2009

XAVIER, I. O discurso cinematográfico - a opacidade e a transparência. Rio de Janeiro: Paz e Terra, 1984.

[Recebido em março de 2012 e aceito para publicação em junho de 2012]

\section{Force of Evil and the intra-class divisions}

Abstract: This article discusses Force of Evil (Abraham Polonsky, 1948) through the analysis of some of its scenes with a focus on two aspects of the narrative: first, how a perspective from the Left on monopolies and capitalism is established in the film; second, the director's view upon the intra-class divisions in the United States of the 1940s.

Keywords: Force of Evil. Abraham Polonsky. John Garfield. Intra-class division. Capitalism.

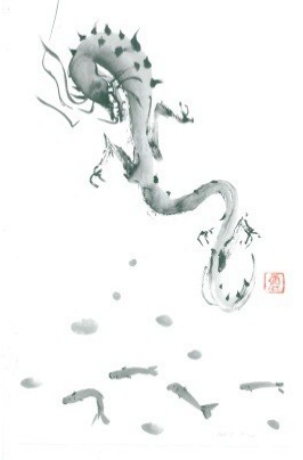

